E3S Web of Conferences 1, 36003 (2013)

DOI: $10.1051 / \mathrm{e} 3 \operatorname{sconf} / 20130136003$

(C) Owned by the authors, published by EDP Sciences, 2013

\title{
Partnership on Reducing Mercury in Artisanal and Small-Scale Gold Mining (ASGM)
}

\author{
L. Bernaudat ${ }^{1}$ and $\underline{\mathrm{S} . \text { Keane }^{2}}$ \\ ${ }^{1}$ United Nations Industrial Development Program, 1.bernaudat@unido.org \\ ${ }^{2}$ Natural Resources Defense Council, skeane@nrdc.org
}

\begin{abstract}
The Artisanal and Small Scale Gold Mining Partnership area is an initiative to reduce global mercury pollution through coordinated voluntary actions. This partnership area, co-led by Natural Resources Defense Council and the United Nations Industrial Development Organization, gathers the major actors in the sector, including governments, academia and civil society. The ASGM sector remains the largest demand sector for mercury globally (best global estimates put mercury use by the sector in the range of 1400 tonne/year in 2011). Virtually all of the mercury introduced in the process is released to the environment. This sector involves an estimated 10-20 million miners, and the numbers are likely increasing as the rising price of gold attracts additional poverty-driven miners. Serious long-term environmental health hazards exist for populations associated with or living downstream/wind from mining operations, often including indigenous peoples. The objective of the ASGM Partnership area is to minimize and where possible eliminate mercury uses and releases in artisanal and small scale gold mining. The presentation will outline the key challenges associated with the ASGM sector and summarize the activities under the Partnership to address those challenges.
\end{abstract}

Key words: mercury, artisanal, small-scale, mining, gold

\section{Introduction}

The Artisanal and Small-Scale Gold Mining (ASGM) sector is the largest use of mercury globally. Best global estimates put mercury use by the sector in the range of 1400 tonne/year in 2011. The sector employs at least 10-20 million miners, although the numbers are likely larger as the high price of gold continues to attract additional poverty-driven miners. Virtually all of the mercury introduced in the process is released to the environment. To address this growing problem, the United Nations established the Artisanal and Small Scale Gold Mining Partnership area as part of UNEP's Global Mercury Partnership, an initiative to reduce global mercury pollution through coordinated voluntary actions. The ASGM partnership area is co-lead by NRDC and UNIDO, and includes Governments, academia and civil society as participating partners.

\section{Materials and Methods}

The objective of the Partnership is continued minimization and elimination of mercury uses and releases in artisanal and small scale gold mining. The
Partnership aspires to achieve a 50 percent reduction in mercury demand in ASGM by the year 2017. However, achieving this reduction is not only a technical issue: sustained behaviour change of miners requires understanding and overcoming social and cultural barriers. Therefore, the Partnership activities provide not only technical information / guidance to miners and mining communities but also work with governments to formalize / regulate the ASGM sector and to address financial, policy and regulatory options which can provide the enabling environment to achieve significant reduction of mercury use and emissions.

\section{Results and Discussion}

In the past two years, the Partnership developed two important documents to provide guidance in these areas: a series of case studies of formalization of the ASGM sector, and a technical guidance on low-mercury and mercury-free technologies. The Partnership has also facilitated a global forum on ASGM involving major ASGM countries from Latin America, Asia and Africa, as well as regional forums in these areas. The Partnership has also provided support for the 
development of national government strategies for addressing the ASGM sector in Asia and Francophone West Africa. Several of the Partners are now involved in implementing a GEF-funded project in Francophone West Africa, building on the Partnership initiatives. Work on developing national action plans will feed directly into expected obligations by countries to develop such plans under the new mercury treaty.

\section{Conclusion}

In the coming year, the ASGM Partnership hopes to expand country-level work on the ground, emphasizing the development of inventories to better characterize the sector, and developing further GEF-funded technical assistance projects in Latin America and Asia. Overall, the Partnership activities will provide critical technical and other information to guide countries as they develop strategies for reducing mercury use in this important sector.

\section{Acknowledgements}

The authors thank the United Nations Environment Programme and all of its member governments for ongoing support for the Partnership Program.

\section{References}

United Nations Environment Programme. Updated Draft Business Plan of the Artisanal and Small Scale Gold Mining. (ASGM) Partnership Area. August 2011. Available at: http://www.unep.org/hazardoussubstances/Mercury/ InterimActivities/Partnerships/ArtisanalandSmallSc aleGoldMining/tabid/3526/language/en-US/Default. aspx. 